\title{
BOREAS

\section{Variations in annual winter mean temperature in South China since 1736}

\author{
LINGLING DING, QUANSHENG GE, JINGYUN ZHENG AND ZHIXIN HAO
}

\section{BOREAS}

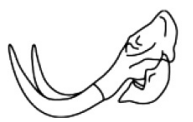

\begin{abstract}
Ding, L., Ge, Q., Zheng, J. \& Hao, Z. 2016 (April): Variations in annual winter mean temperature in South China since 1736. Boreas, Vol. 45, pp. 252-259. 10.1111/bor.12144. ISSN 0300-9483.

Modern meteorological observations in South China from 1960 to 2009 show a strong correlation between winter temperatures and two snowfall parameters, the southern boundary of the snow and the number of snowy days. Based on this relationship, the variation in annual winter mean temperature in South China from 1736 to 2009 was reconstructed using data acquired from Chinese historical documents dating from the Qing dynasty, such as memos and local gazettes. The reconstructed time series were used to analyse variations in winter temperature in South China. Significant interannual and interdecadal changes were found. The maximum temperature difference between neighbouring years was $3.1^{\circ} \mathrm{C}$ for $1958-2009$ and $3.0^{\circ} \mathrm{C}$ for $1736-1957$, whereas the maximum temperature difference between adjacent decades was $0.8{ }^{\circ} \mathrm{C}$ for the $1960 \mathrm{~s}-2000 \mathrm{~s}$ and $0.6{ }^{\circ} \mathrm{C}$ for the $1740 \mathrm{~s}-1950 \mathrm{~s}$. The 2000 s was the warmest decade; the mean temperature was $1.6^{\circ} \mathrm{C}$ higher than that of the $1870 \mathrm{~s}$, which was the coldest decade between the 1740 s and the 2000s. The mean winter temperature was warmer in the 18 th and 20th centuries and coldest in the 19 th century.
\end{abstract}

Lingling Ding, Quansheng Ge, Jingyun Zheng and Zhixin Hao (corresponding author: haozx@igsnrr.ac.cn), Key Laboratory of Land Surface Pattern and Simulation, Institute of Geographic Sciences and Natural Resources Research, Chinese Academy of Sciences, Beijing 100101, China; Lingling Ding, Institute of Han River, Hubei University of Arts and Science, Xiangyang 441053, China; received 13th January 2015, accepted 16th August 2015.
In winter, cold air activity affects most regions of China. Cold air entering eastern China follows three main paths: a western path, moving south through the area west of $105^{\circ} \mathrm{E}$; a central path, moving south through the Hetao region (from 105 to $115^{\circ} \mathrm{E}$ ); and an eastern path, moving south through the area east of $115^{\circ}$ E. Cold air from the western path reaches South China frequently, and the arrival of cold air does not always correspond to cold air activity. However, during colder winters, more cold air breaks away from the middle and eastern paths and even affects regions further south, bringing cold conditions to large areas of China (Zhang \& Gong 1979). Therefore, when South China experiences cold periods caused by strong cold air activity, most of China is cold.

Winter in South China is warmer than in other regions of China because South China is closer to the equator. However, the winter weather can also be influenced by cold air moving in from high-latitude regions during winter. Therefore, the mean winter temperature in South China is higher than in North China, and there are fewer snowy or freezing days than at other latitudes. When cold air comes in from the north, the temperature in South China shows a large, abrupt decrease, with mean drop of more than $10{ }^{\circ} \mathrm{C}$ for recent years in most regions. This affects subtropical plants and can kill them over a large area (Lu 2012). There are many records of cold winters in South China that mainly document snowfall, freezing of rivers and lakes, and damage to plants. These records provide important evidence for studying variations in warm and cold winters in South China. Moreover, related historical records from documents such as local gazettes have been used to reconstruct time series of warm and cold winters in South China over the past 500 years (Zhang 1980; Wang et al. 1998; Xue et al. 2004; Zheng et al. 2012), at resolutions of $\geq 10$ years. There is also an archive of official Chinese historical records of rainfall (Yu) and snowfall (Xue) in units of fen (length unit, $\sim 0.32 \mathrm{~cm}$ ) and cun $(\sim 3.20 \mathrm{~cm})$, known as 'Yu-Xue-Fen-Cun' records. The rainfall data are recorded as rainfall infiltration depth in the ground, and the snowfall data as the accumulative depth of snowfall for each weather event. Thus, Yu-Xue-Fen-Cun records can provide data with daily temporal resolution. By using these high-resolution snowy day records, series of mean winter temperatures with annual time resolution have been reconstructed for the period since 1736 at some sites (Ge et al. 2005; Hao et al. 2012). There are no studies using these data for South China because there are fewer records and less accurate information for specific sites. However, the warm-cold records for one site can represent a larger area; if we combine records within larger areas and count snowy days, the inhomogeneous data problem caused by missing and sporadic records can be solved (Gong et al. 1983). In addition, the southern boundary of the snowfall can reflect the intensity of a cold winter. In this study, we reconstructed the variations in mean annual winter temperature in South China since 1736 for several stations. We used two key snowfall parameters, the southern boundary of the snowfall and the number of snowy days, and extracted data from Yu-Xue-FenCun records, local gazettes and other historical documents. The reconstructed series were then used to analyse winter warm-cold variations in South China over the past 300 years. 


\section{Data and methods}

\section{Data sources}

The research material consists of written material with related descriptive records and modern meteorological observations. Figure 1 shows the main meteorological sites and ancient counties with snowfall records in South China.

The written material includes Yu-Xue-Fen-Cun records, local gazettes and other historical documents. Yu-Xue-Fen-Cun records, contained in Qing dynasty archives of memos sent to the Emperor, record the rainfall infiltration depth in the ground and the depth of snowfall, measured in fen and cun units. They also contain qualitative descriptions of weather conditions and other relevant information for each period, covering the three provinces of Fujian, Guangdong and Guangxi in South China from 1736 to 1911. However, comparing these records with detailed records in other regions, such as Hefei, reveals that there are no continuous snowfall data for South China, because the local climate was characterized by abundant precipitation and occasional snowfall episodes. For instance, Guilin has the largest number of snowfall records in South China, with 71 years recording snowfall and 68 years listing exact dates, corresponding to $38.6 \%$ of the 176 years (1736-1911) covered by the records, much less than Hefei, where $86.4 \%$ of the years were recorded as snowy years (Zhou et al. 1994).

To compensate for this lack of information in the archive, we also collected related warm-cold records of snowy or freezing days from compilations of meteorological records extracted from historical Qing dynasty documents, including the compilations by Zhang (2013), Ding (2008) and new local gazettes of administrative districts in South China. These records can be used to verify the data and are reliable because of the thorough revisions made during the collection and compilation of the records. In addition, for the period of 2001 to 2010 , some data were collected from almanacs, articles and newspapers.

A total of 2663 records from stations was collected from written material, of which about 1500 records were from the Yu-Xue-Fen-Cun archive, covering 10 stations with an annual time resolution. The decade with the most records had 23 stations, whereas the decade with fewest records had only two stations. The Yu-

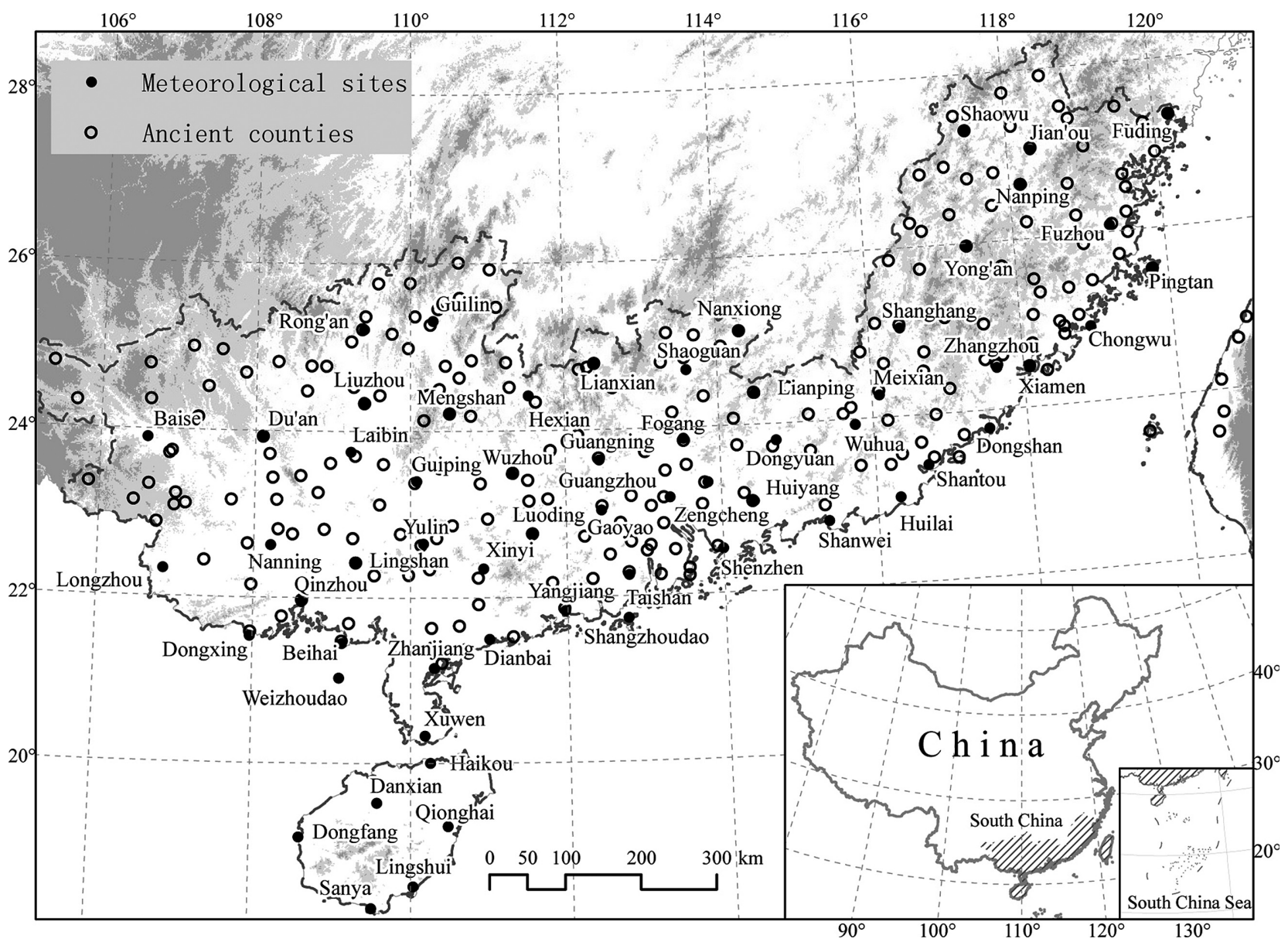

Fig. 1. Location of selected meteorological sites and main ancient counties with snow records in South China. 
Xue-Fen-Cun archive is more reliable and accurate than historical information from local gazettes and other historical literature (Ge \& Zhang 1990). However, the temporal distribution of the Yu-Xue-Fen-Cun archive is uneven in South China, with more records dating from the reign of the Qianlong Emperor (17361795 ) and fewer after this period. For example, for Guilin, only 68 years of records bearing the exact date were obtained during the period 1796-1911, which accounted for $65.9 \%$ of the period, with 48 years of these records documented in the 60-year reign of the Qianlong Emperor. For instance, in the Yu-Xue-FenCun archive, Liang Zhangju, Governor General of Guangxi, reported 'About 2 to 3 cun of snow fell during the 26th to 28th day of the 11th month (19-21 December in the Gregorian calendar) according to reports in Lingui, Lingchuan, Xing'an, Guanyang, Quanzhou of Guilin Fu, Pingle, Lipu, Xiuren of Pingle $\mathrm{Fu}$, and Maping of Liuzhou Fu' on the 28th day of the 12th month of the lunar calendar (19 January 1841) during the 20th year of the Daoguang Emperor (1840). Moreover, most records in local gazettes and other documents are of abnormal snowfall events, covering large areas for a long time, rather than records of exact dates and locations, although they can be used to verify each other and the records in the Yu-Xue-Fen-Cun archive. Therefore, we used all of this information, including the Yu-Xue-Fen-Cun archive, local gazettes and other documents, to improve the reliability of data for our reconstruction.

Modern meteorological data were downloaded from the China Meteorological Data Sharing Service Network (http://cdc.cma.gov.cn/home.do), and included winter temperatures from December to February and snowfall information from 1 November to 31 March. The data are quality controlled by the Chinese Meteorological Administration before release. The data set contained 84 meteorological sites in South China (Fujian, Guangdong, Guangxi and Hainan provinces) with mean monthly temperature records for the winters from 1958 to 2009. We chose 61 sites (meteorological sites in Fig. 1) to compute the mean winter temperature in South China, considering the recording period, spatial coverage and altitude. The snowfall information was obtained from three classes of record. The first class is the daily precipitation record in South China for 1951-1979, in which snowfall information can be identified from the codes 31XXX, meaning 'snow mixed with sleet' or 'snowstorm' and 30XXX, meaning 'rain and snow'. The second class is snow records compiled from 1971 to 2008, collected from the Report of Monthly Surface Meteorological Records in China during 1971-1996 and the Book of Monthly Surface Meteorological Records in China during 1997-2008, which have also been quality controlled by the Chinese Meteorological Administration. Snowfall in these records is identified by a snowflake symbol $(*)$ in precipitation data or a digital code for meteorological phenomena, such as ' 68 ' for mixed snow and sleet or ' 70 ' for snow. The third class consists of snow records from other databases, including Daily Precipitation Data in China from 1951 to 1970 (Central Weather Bureau 1975), in which snow phenomena are identified by a snowflake symbol, and the Days of Weather Phenomena Data in China from 1961 to 1970 (Central Weather Bureau 1978), in which snowy days are recorded. Considering the differences in recording sites and inconsistencies in the information contained in these three types of record, we collected and calibrated the data by using all of these databases.

\section{Collection methods for snowfall indices to reconstruct winter temperatures}

Weather processes in winter are mostly caused by cold air activity, with decreasing temperature, strong gales, sleet and snow, and freezing spells accounting for the main winter disasters in South China (Ding 2013). Thus, the winter temperature is strongly affected by the frequency, intensity and duration of cold air activity. The southern boundary of weather phenomena caused by cold air activity can indicate the degree of activity, whereas the number of weather phenomena lasting several days also indicates the frequency and duration of the activity. Thus, considering the features of the historical data for South China, we reconstructed the variation in winter temperature from the southern boundary of the snowfall and the number of snowy days. To allow for missing historical information, we collected historical data from November and March rather than from December to February, because snowfall in November and March can provide evidence of cold weather when there are no records from December to February. There is a strong relationship between mean winter temperature and the number of snowy days recorded from November to March and from December to February in South China during 1960-2009, with correlation coefficients of -0.53 and -0.52 (statistical significance: $p<0.001$ ), respectively.

The southern boundary of snowfall is defined as the latitude of the southernmost site where snow occurred. We identified the latitudes of sites to a precision of $0.1^{\circ}$ from the historical documents according to the location of the sites marked on the administrative map in the 25th year of the Jiaqing Emperor (1820) in The Historical Atlas of China compiled by Tan (1982). As most regions of South China are located south of $26^{\circ} \mathrm{N}$ and Ziyuan county in Guangxi province $\left(26^{\circ} \mathrm{N}\right)$ has 11 days of snowfall on average, we took $26^{\circ} \mathrm{N}$ as the maximum value for the parameter of the southern snowfall boundary. Thus, the southern snowfall boundary was recorded as $26^{\circ} \mathrm{N}$ even when the latitude was recorded as further north than $26^{\circ} \mathrm{N}$ in the historical documents. 
The number of snowy days was recorded as the maximum number of snowy days in representative sites because few sites had continuous snowfall records. Nanling and other mountains located in the northernmost region of South China block the entry of cold air southward, causing clear climate differences between the regions north and south of the mountains. Thus, snowy days in this area represented the frequency and duration of cold air activity. We chose representative sites with altitudes $<1000 \mathrm{~m}$ a.s.l. and within $50 \mathrm{~km}$ of the northern border of southern subtropical areas, identified from the temperatures in Zheng et al. (2010) along the border with Nanling. Finally, we took the maximum number of snowy days from all representative sites from November to March to represent the number of snowy days for South China. Taking the winter of 1958-1959 as an example, there are two representative sites, Nanxiong and Rong'an, that have snowfall records with 1 and 3 days of snow, respectively, so three snowy days were recorded for this winter. For qualitative records, where the number of snowy days in representative sites could not be obtained directly, we established the following criteria for counting the number of snowy days after examining documents for all years with similar records. First, for years with snowfall records in several sites south of the representative sites, the number of snowy days was taken as the number of snowy days recorded. Taking the winter of $1750-1751$ as an example, Shu $\mathrm{Lu}$, the Governor General of Guangxi, reported 'About 1 to 3 cun of snow fell during the 28th to 30 th day of the 11th month (26-28 December) in Yong'an, Pingle, Gongcheng, Fuchuan, Hexian, Xiuren, Lipu, Zhaoping of Pingle Fu, Maping, Luorong, Laibin of Liuzhou Fu, Yishan, Sien of Qingyuan Fu, Binzhou, Qianjiang of Sien Fu' during the 15th year of the Qianlong Emperor (1750) in the memos. Therefore, three snowy days were recorded because there are several sites located south of the representative sites (Laibin, Binzhou, Qianjiang, etc.) that had snow and it is possible that some of the representative sites had three snowy days. Second, in years recording more than three snowy days for at least three sites located north of the representative sites and at least two representative sites, the number of snowy days was taken as one-third (mean value from one-seventh to twothirds) of the total recorded snowfall days based on 7 years of similar observation records from 1951 to 1980. Taking the winter of $1828-1829$ as an example, Han Kejun, the Governor General of Fujian, reported 'Snow successively fell during the 8th, 9th, 11th, 14th, 15th and 30th day of the 12th month $(12,13,15,18$, and 19 January and 3 February) in the counties of Minxian, Houguan, Luoyuan, Pingnan, Nanping, Jiangle, Pucheng, Songxi, Zhenghe,
Guangze, Wuping, Xiapu, Fuding, Fu'an, Ningde and Shouning' on the 29th day of the 1st month of the lunar calendar, during the 9th year of the Daoguang Emperor (4 March 1829) in the memos. The number of snowy days was estimated as two because there were many sites (Pingnan, Nanping, Jiangle, Pucheng, Songxi, Zhenghe, Guangze, Xiapu, Fuding, Fu'an, Ningde and Shouning in this record) north of the representative sites that recorded snow and it was less likely that all representative sites (Minxian, Houguan, Luoyuan and Wuping) had six snowy days. Third, for years without recorded dates or durations, records of 'heavy snow' were taken as two snowy days, and records of 'light snow' or 'snow' were taken as 1 day.

During historical periods, for years without snow records (33 years, $15.6 \%$ of 212 years) or without records at the representative sites (83 years, 39.2\% of 212 years), the southern snowfall boundary and the number of snowy days were defined as 'no data', because we could not find additional related snowfall information, and it was difficult to distinguish no snowfall from missing data. However, after 1949, the southern boundary of snowfall and the number of snowy days in years without snow records $(2$ and 8 years, respectively) were interpolated as $26^{\circ} \mathrm{N}$ and 0 , respectively, because records in this period were almost complete and fewer snowfall events were missed.

\section{Winter temperature reconstruction methods}

Although we did not derive the number of snowy days from individual sites, there is a significant negative correlation between mean winter temperatures and the number of snowy days in South China (Zhou et al. 1994; Wu et al. 2011; Hao et al. 2012). The correlation coefficient is -0.53 (statistical significance: $\mathrm{p}<0.001$ ) between winter mean temperature and the number of snowy days in South China from 1960 to 2009 . There is a significant positive correlation (correlation coefficient $0.54, \mathrm{p}<0.001$ ) between mean winter temperature and the southern snowfall boundary. Considering the high correlation between the number of snowy days and the southern snowfall boundary (correlation coefficient -0.60) and the large amount of missing historical data, we built regression models to compare the southern snowfall boundary $\left(X_{1}\right.$, degrees) or maximum number of snowy days $\left(X_{2}\right.$, days) and the mean winter temperature ( $Y$, degrees Celsius) in South China from 1960 to 2009 using modern meteorological observations. We reconstructed two temperature series based on the two regression models; the annual mean winter temperature series was reconstructed by choosing the minimum value of the two series (Fig. 2). The regression equations were: 


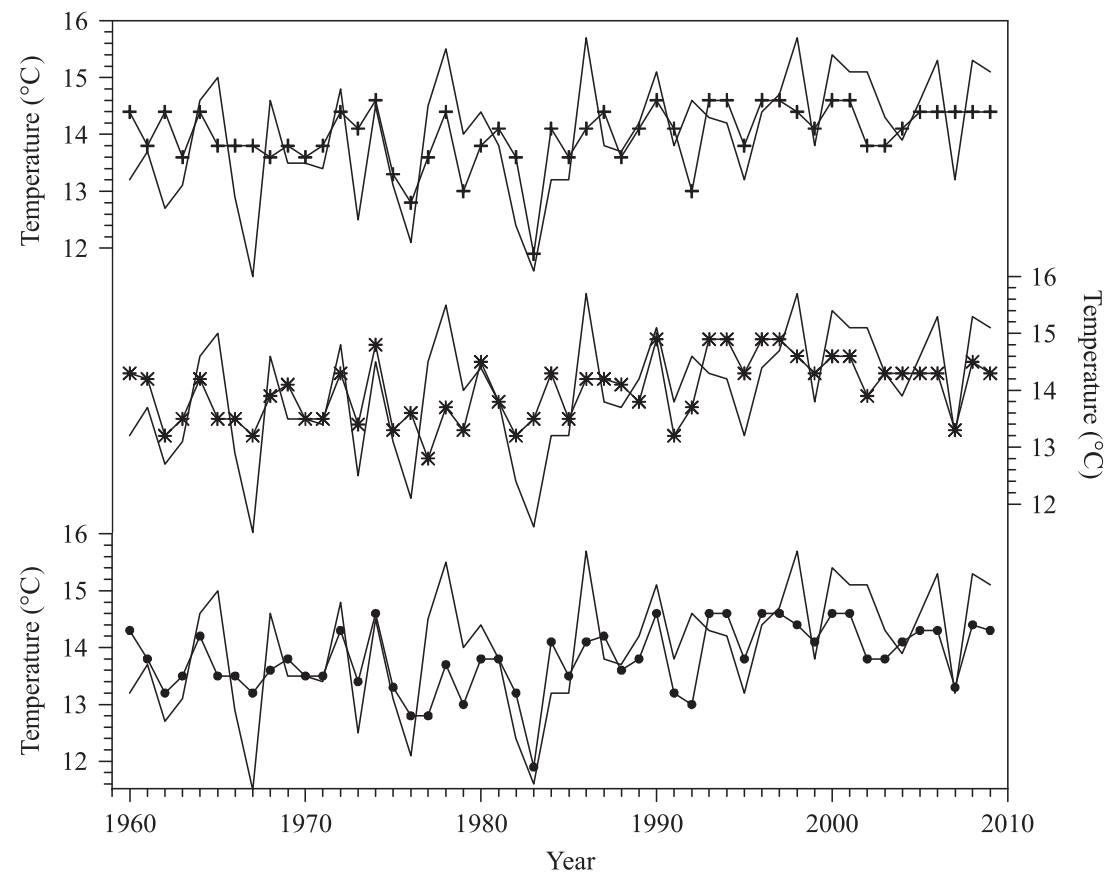

Fig. 2. Series of observed and reconstructed temperatures in South China for 1960-2009. Thin solid lines: observed temperature; lines with cross: reconstructed temperatures obtained from the southern snowfall boundary; lines with asterisks symbols: reconstructed temperatures obtained from the number of snowy days; lines with filled circles: combined series.

$$
\begin{gathered}
Y=2.48+0.48 X_{1} \\
Y=14.64-0.27 X_{2} .
\end{gathered}
$$

The total explained variance of the final reconstructed data was 0.37 after choosing the minimum value between the two series, which was larger than that of the two regression equations $\left(R^{2}=0.29\right)$. The absolute error of the combined series was 32.67 ; thus, the error was reduced by 2.42 and 2.22 compared with the errors of Equations 1 and 2 of 35.09 and 34.89, respectively. Thus, this method is reasonable for reconstructing annual mean winter temperature variation in South China since 1736. The correlation coefficients between the observed and the reconstructed temperatures derived from Equations 1 and 2 and the combined series are $0.55,0.53$ and 0.64 , respectively, and those between the combined series and the series from Equations 1 and 2 are 0.87 and 0.86 , respectively. All correlation coefficients are above the 0.01 significance level.

\section{Results and analysis}

The mean winter temperatures for 1736-1957 were obtained according to the methods described above. The series of data obtained by using modern meteorological methods for 1958-2009 and the mean annual winter temperatures in South China for 1736-2009 are shown in Fig. 3. The 95\% confidence interval for the reconstructed value from independent variable $X$, $Y_{X}$, is $Y_{X} \pm t_{0.025, N-2} \sigma\left(1 / N+\left(X-X_{m}\right)^{2} / \mathrm{SSX}\right)^{0.5}(N=50)$, where the estimated SD, $\sigma$, is 0.83 from the combined series, and $X, X_{m}$ and SSX are the estimated value, mean value and sum of squares of deviations of the series from which the reconstructed value is obtained, respectively (Fig. 3; Richard \& Dean 2007). There are 33 missing years in the series, which has a small effect on the interannual and interdecadal variability of the reconstructions because it is less likely that large snow events occurred in years without snow records. In addition, other records of disasters such as droughts and floods were found in most of these years, it is unlikely that the other extreme climate events were omitted, as records are abundant over the last 300 years compared with other historical periods.

\section{Reliability analysis}

To analyse the reliability of our method and results, we compared the reconstructed winter temperature series (series D, Fig. 4; anomalies in mean temperatures from the 1970 s to 1990 s) with other published cold-warm series in South China on decadal time scales reconstructed from historical documents other than the Yu-Xue-Fen-Cun archives. The series consisted of the winter-half-year temperature series in eastern China from the 1740s to the 1990s (series A, Fig. 4; Ge et al. 


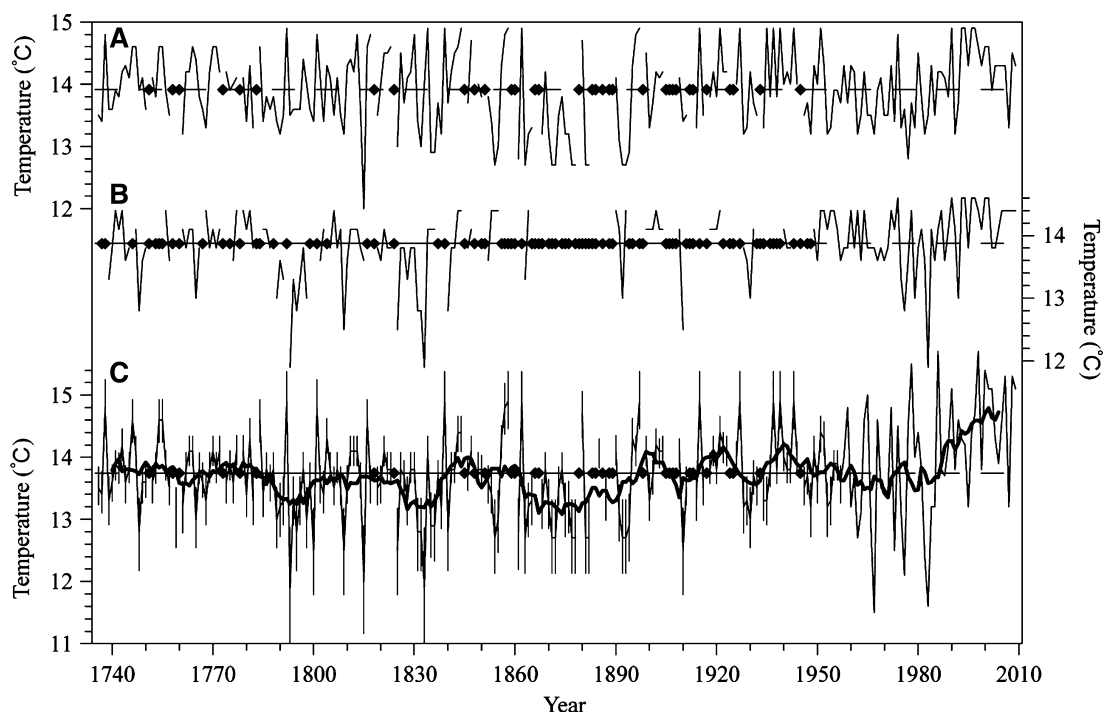

Fig. 3. Annual winter mean temperature series in South China for 1736-2009. Dashed horizontal lines: mean value of series for 1736-2009; squares: years defined as 'no data'. A. Thin solid line: reconstructed temperature series obtained from the southern snowfall boundary for 1736-2009. B. Thin solid line: reconstructed temperature series obtained from the number of snowy days parameter for 1736-2009. C. Thin solid line: combined temperature series for 1736-1957 and observational temperature for 1958-2009; thick line: 10-year moving average; grey line: $95 \%$ confidence interval for $Y_{X}$.

2003), the decadal mean temperature anomaly series in South China from the 1740 s to the 1990 s (series B, Fig. 4; Wang et al. 1998) and the winter temperature index series in subtropical and tropical zones from the 1740 s to the 1960s (series C, Fig. 4; Zhang 1980; Guangzhou, Nanning and Haikou as representative sites). The following conclusions can be drawn from the results in Fig. 4: (i) although the study regions for these series were not identical, they had similar cold and warm periods, such as cold periods in the 1830 s, 1870 s and 1880 s, and a warm period from the 1920 s to the 1950s; (ii) for series B, C and D in Fig. 4 for South China, there are several similar temperature variations, which are different from those of series $\mathrm{A}$ in eastern China, such as two warm decades around the cold periods in the $1830 \mathrm{~s}$. In addition, the warm period in the 1860s in series A in Fig. 4 was not present in the South China series.

As the winter temperatures from 1958 onwards were obtained with modern instruments, we only calculated the correlation coefficients between the series from the 1740s to the 1950s (reconstructed periods) for the reliability analysis. The Pearson correlation coefficients between series D and series A, B and C for the decadal values are $0.64(\mathrm{p}<0.001), 0.59$ $(p<0.005)$ and $0.72(p<0.001)$, respectively. Thus, there are significant correlations and similarities between the mean winter temperature series in South China in this study and other publications, indicating that our results can be used to analyse climate variation in South China.

\section{Interannual and interdecadal variation}

The interannual and interdecadal variations are shown in Figs 3 and 4. The maximum winter temperature amplitude was $4.2^{\circ} \mathrm{C}$ for 1958-2009 (maximum temperature of $15.7^{\circ} \mathrm{C}$ in 1986 and 1999 , minimum temperature of $11.5^{\circ} \mathrm{C}$ in 1967), whereas the maximum winter temperature amplitude was $3.0 \pm 0.3{ }^{\circ} \mathrm{C}$ for 1736-1957. The SD for running windows of 10 years for $1736-1957$ was 0.3 . The interannual maximum temperature difference between neighbouring years of $3.1^{\circ} \mathrm{C}$ for 1958-2009 occurred between 1967 and 1968 , and that of $3.0 \pm 0.3{ }^{\circ} \mathrm{C}$ for $1736-1957$ occurred between 1792 and 1793 .

On the decadal time scale, the warmest decade was the 2000s, and its temperature was $1.6^{\circ} \mathrm{C}$ higher than that of the $1870 \mathrm{~s}$, which was the coldest decade from the 1740 s to the 2000 s. The 1990 s was the second warmest decade, $0.5{ }^{\circ} \mathrm{C}$ warmer than the mean temperature from the 1970s to the 1990s. The maximum temperature difference between adjacent decades of $0.8^{\circ} \mathrm{C}$ for the $1960 \mathrm{~s}-2000 \mathrm{~s}$ occurred between the $1980 \mathrm{~s}$ and the $1990 \mathrm{~s}$, and that of $0.6 \pm 0.3{ }^{\circ} \mathrm{C}$ for the $1740 \mathrm{~s}-1950 \mathrm{~s}$ occurred between the $1830 \mathrm{~s}$ and the 1840 s. The climate during the 1740 s to the 1910 s and the 1930 s to the 1980 s was colder than the mean temperature from the 1970 s to the 1990 s by $0.8 \pm 0.3{ }^{\circ} \mathrm{C}$ in the $1870 \mathrm{~s}$ and by $0.6 \pm 0.3{ }^{\circ} \mathrm{C}$ in the $1790 \mathrm{~s}$ and the 1830s. In addition, on the centennial scale, the mean annual winter temperature was highest in the 18th and 20 th centuries, whereas it was lower in the 19th 


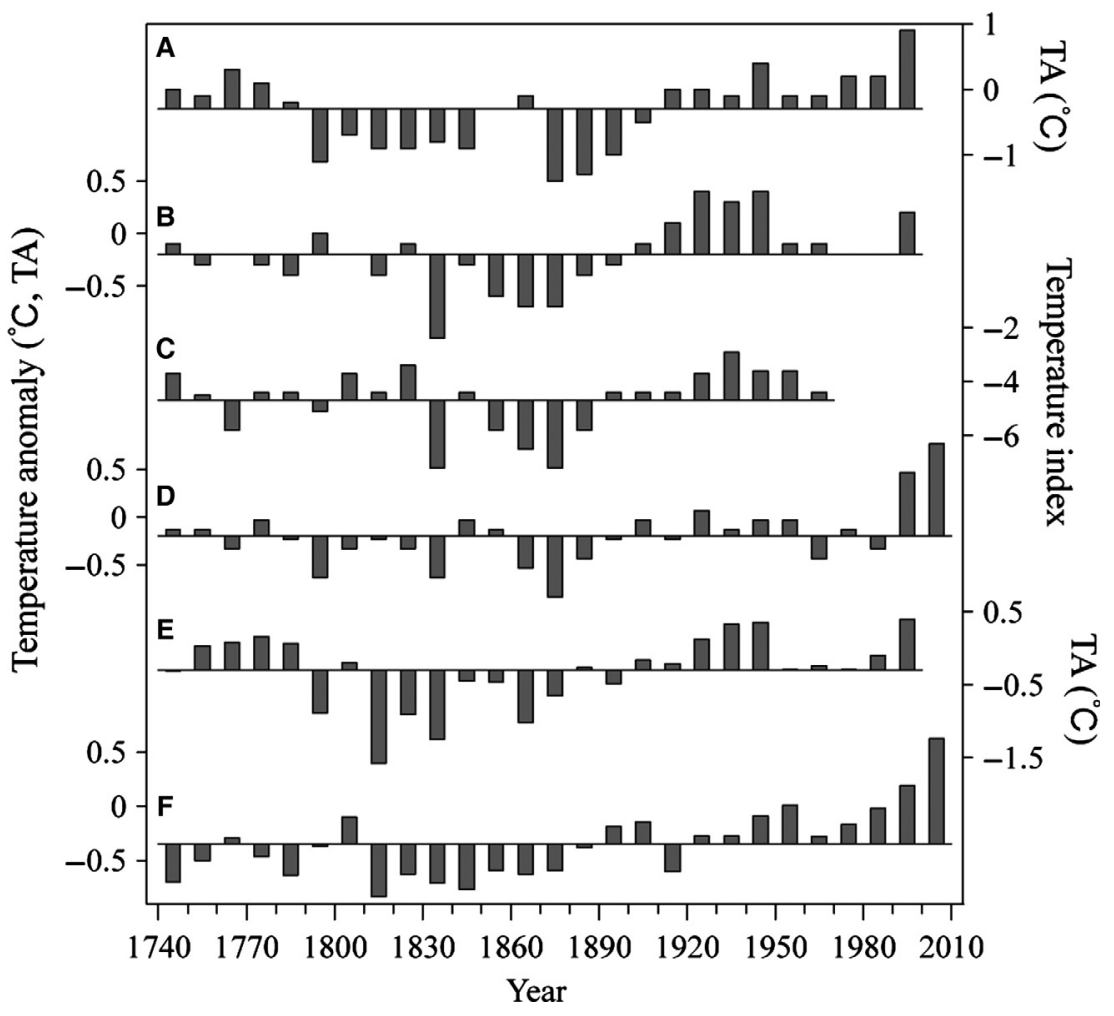

Fig. 4. Comparison of winter mean temperature in South China and temperature series for southern China, eastern China, the whole of China or East Asia. Baselines: mean value of series. Series A: winter-half-year temperature series in eastern China from the 1740s to the 1990s (Ge et al. 2003). Series B: decadal mean temperature anomaly series in South China from the 1740s to the 1990s (Wang et al. 1998). Series C: winter temperature index series in subtropical and tropical zones from the 1740s to the 1960s (Zhang 1980; taking Guangzhou, Nanning and Haikou as representative sites). Series D: our reconstructed winter temperature series (anomalies in mean temperatures from the 1970s to the 1990s). Series E: temperature changes in China from 1740s to 1990s (Ge et al. 2013). Series F: tree ring-based reconstruction of summer temperature anomalies for East Asia from 1740s to 2000s (Cook et al. 2013).

century by $0.3{ }^{\circ} \mathrm{C}$ compared with the 20th century and by $0.2{ }^{\circ} \mathrm{C}$ compared with the 18 th century.

\section{Conclusions}

We reconstructed the mean annual winter temperature series in South China during 1736-2009 from climate features and the available historical information. We combined information from many weather stations and used the southern snowfall boundary and the number of snowy days as key indices. The series were used to analyse variations in winter temperature in South China over the past 300 years.

Clear interannual and interdecadal changes in winter temperature were seen. The maximum temperature difference between neighbouring years was $3.1^{\circ} \mathrm{C}$ for 1958-2009 and $3.0^{\circ} \mathrm{C}$ for $1736-1957$, which occurred at 1967-1968 and 1792-1793, respectively, and the maximum temperature difference between adjacent decades was $0.8{ }^{\circ} \mathrm{C}$ for the $1960 \mathrm{~s}-2000 \mathrm{~s}$ and $0.6{ }^{\circ} \mathrm{C}$ for the $1740 \mathrm{~s}-1950 \mathrm{~s}$, which occurred at the $1830 \mathrm{~s}-1840 \mathrm{~s}$ and 1970s-1990s. The 2000s was the warmest decade, and its mean temperature was $1.6^{\circ} \mathrm{C}$ higher than that of the coldest decades. The mean winter temperature was relatively warm in the 18th and 20th centuries compared with the 19th century.

The reconstruction of winter temperatures with annual resolution is useful for studying historical winter climate change in South China and the whole of China, because there are fewer snowfall records and less snowy weather in South China than in North China. Although large uncertainties still exist in the reconstruction results for South China compared with those for North China and the Yangtze River Valley (Zhou et al. 1994; Wu et al. 2011; Hao et al. 2012), which were obtained using more accurate records and better instrumental data, our results are supported by their similarity to other winter temperature series and winter temperature index series in South China or eastern China reconstructed previously.

The correlation coefficient between the reconstructed winter temperature series (series D, Fig. 4) and temperature changes in China (series E, Fig. 4; Ge et al. 2013) is $0.60(\mathrm{p}<0.005)$, whereas that between series D in Fig. 4 and the tree ring-based reconstruction of summer temperature anomalies for East Asia (series F, Fig. 4; Cook et al. 2013) is $0.62(\mathrm{p}<0.005)$. We also compared the winter temperature change between 
South China and larger areas, such as China and East Asia. Before the 1790s, climate conditions were warmer in China and colder in East Asia (Fig. 4), although no clear trend was detected in South China, where the climate alternated between cold and warm conditions. Some consistent variations can be found in all temperature series over South China, whole China and East Asia. For example, the coldest century from 1801 to 1900 , and the warmest period in the 20th century. These similarities and differences may arise from the proxy data and regional features. However, our reconstruction provides new evidence for future analysis of temperature variations on a larger spatial scale.

Acknowledgements. - This study was jointly funded by the Strategic Priority Research Program of the Chinese Academy of Sciences (grant no. XDA05080100) and the Institute of Geographic Sciences and Natural Resources Research (grant no. 2014RC101).

\section{References}

Central Weather Bureau 1975: Daily Precipitation Data in China from 1951 to 1970. 681 pp. Central Weather Bureau, Beijing (in Chinese).

Central Weather Bureau 1978: Days of Weather Phenomena Data in China from 1961 to 1970.741 pp. Central Weather Bureau, Beijing (in Chinese).

Cook, E. R., Krusic, P. J., Anchukaitis, K. J., Buckley, B. M., Nakatsuka, T. \& Sano, M. 2013: Tree-ring reconstructed summer temperature anomalies for temperate East Asia since $800 \mathrm{CE}$. Climate Dynamics 41, 2957-2972.

Ding, Y. H. 2008: China Meteorological Disaster Canon. 948 pp. China Meteorological Press, Beijing (in Chinese).

Ding, Y. H. 2013: Climate of China. Physical Geography of China, Monograph Series. 557 pp. Science Press, Beijing (in Chinese).

Ge, Q. S. \& Zhang, P. Y. 1990: The evaluation on climatic information in the historical literatures. Acta Geographica Sinica 45, 22-30 (in Chinese).

Ge, Q. S., Hao, Z. X., Zheng, J. Y. \& Shao, X. M. 2013: Temperature changes over the past $2000 \mathrm{yr}$ in China and comparison with the Northern Hemisphere. Climate of the Past 9, 1153-1160.

Ge, Q. S., Zheng, J. Y., Fang, X. Q., Man, Z. M., Zhang, X. Z., Zhang, P. Y. \& Wang, W. C. 2003: Winter half-year temperature reconstruction for the middle and lower reaches of the Yellow River and Yangtze River, China, during the past 2000 years. Holocene 13, 933-940.

Ge, Q. S., Zheng, J. Y., Hao, Z. X., Zhang, P. Y. \& Wang, W. C. 2005: Reconstruction of 1736-1911 high resolution precipitation over China using historical archives of the Qing Dynasty. Bulletin of the American Meteorological Society 86, 671-679.

Gong, G. F., Zhang, P. Y., Wu, X. D. \& Zhang, J. R. 1983: Research Methods of Climate Change in Historical Period. 302 pp. Science Press, Beijing (in Chinese).

Hao, Z. X., Zheng, J. Y., Ge, Q. S. \& Wang, W. C. 2012: Winter temperature variations over the middle and lower reaches of the Yangtze River since 1736AD. Climate of the Past 8, 1023-1030.

Lu, S. J. 2012: Climate in Fujian. 520 pp. Meteorological Press, Beijing (in Chinese).

Richard, A. J. \& Dean, W. W. 2007: Applied Multivariate Statistical Analysis. 800 pp. Pearson Education, New York.

Tan, Q. X. 1982: The Historical Atlas of China. 549 pp. Sinomaps Press, Beijing (in Chinese).

Wang, S. W., Ye, J. L. \& Gong, D. Y. 1998: Climate in China during the Little Ice Age. Quaternary Sciences 28, 54-64 (in Chinese).

Wu, G. F., Hao, Z. X. \& Zheng, J. Y. 2011: Reconstruction of snowfall and winter temperature variations in Nanchang since 1736. Quaternary Sciences 31, 1022-1028 (in Chinese).

Xue, J. B., Zhong, W., Zhao, Y. J. \& Peng, X. Y. 2004: The preliminary study on the characters of climate and disasters in Guangdong province during the 15th-19th century. Journal of South China Normal University 36, 123-131 (in Chinese).

Zhang, D. E. 1980: Winter temperature changes during the last 500 years in South China. Chinese Science Bulletin 25, 497500 .

Zhang, D. E. 2013: Collection of the Climate Records in China during the Three Thousand Years: Revised Edition. 3795 pp. Phoenix Education Publishing, Nanjing (in Chinese).

Zhang, P. Y. \& Gong, G. F. 1979: Some characteristics of climatic fluctuations in China since 16th century. Acta Geographica Sinica 34, 238-247 (in Chinese).

Zheng, J. Y., Ding, L. L. \& Hao, Z. X. 2012: Extreme cold winter events in southern China during AD 1650-2000. Boreas 41, 1-12.

Zheng, J. Y., Yin, Y. H. \& Li, B. Y. 2010: A new scheme for climate regionalization in China. Acta Geographica Sinica 65, 3-13 (in Chinese).

Zhou, Q. B., Zhang, P. Y. \& Wang, Z. 1994: Reconstruction of annual winter mean temperature series in Hefei area during 1736 to 1991 AD. Acta Geographica Sinica 49, 332-337 (in Chinese). 